\title{
Combined Use of Needle-Knife and Bite Biopsy in the Diagnosis of a Gastric Submucosal Tumor
}

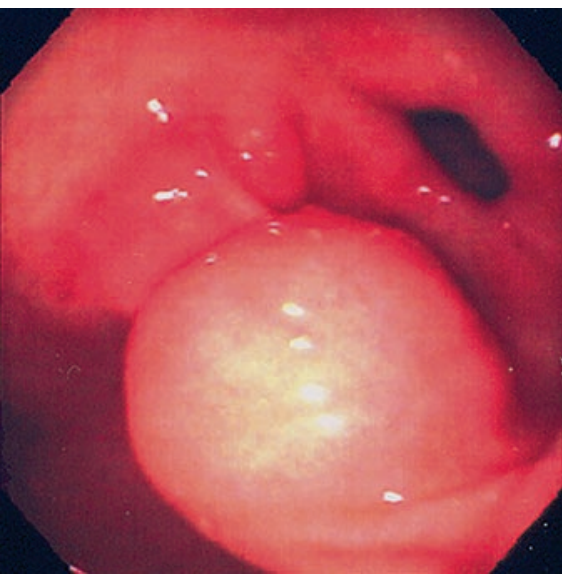

Figure 1 Endoscopic view of a large antral submucosal tumor located in the greater curvature of the stomach, $3 \mathrm{~cm}$ from the pylorus. The mucosa covering the mass did not differ from the surrounding antral mucosa.

A 60-year-old woman was admitted to hospital for evaluation of symptomatic anemia. Esophagogastroduodenoscopy revealed a submucosal gastric tumor in the antrum (Figure 1) and probing of this tumor with the tip of the biopsy forceps revealed that it had a solid consistency. A Huibregtse needle-knife (Wilson-Cook, Winston-Salem, North Carolina, USA) was then inserted into the working channel of a standard Olympus Q160 gastroscope (Olympus America, Melville, New York, USA). Once the needle-knife was exposed, a linear incision was made on the center of the submucosal gastric tumor (Figure 2). The incision was performed by moving the up/down control of the endoscope handle, and the depth of the incision was determined by exposing two-thirds of the needle length and by advancing or retracting the shaft of the Huibregtse needleknife catheter from the endoscopic channel. After an incision $1.5 \mathrm{~cm}$ in length had been made (Figure 3), a biopsy forceps (Microvasive Inc., Natick, Massachusetts, USA) was placed in the submucosal mass through the incision. The forceps was opened inside the submucosal gastric tumor and six bites of submucosal tissue were obtained. Histology revealed an adenocarcinoma that was most consistent with a metastatic colon cancer. Colonoscopy confirmed a right-sided colon cancer.

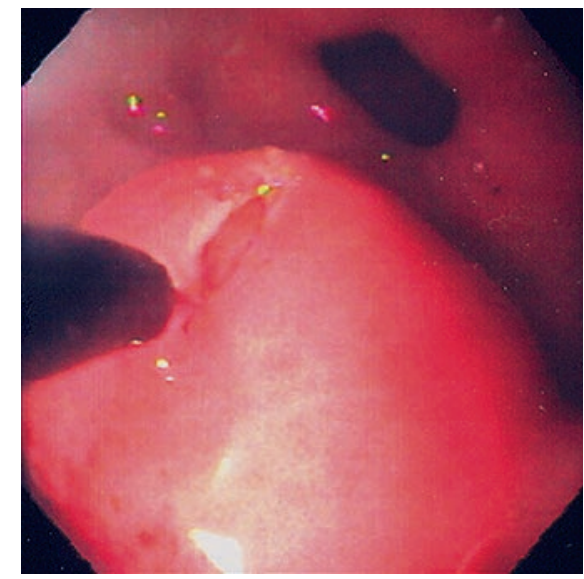

Figure 2 The needle-knife was advanced through the working channel of the endoscope until two-thirds of the total length of the needle-knife was exposed. Pure cutting electrical current was then applied using the ERBE electrosurgical generator.

Several endoscopic methods have been described for the retrieval of tissue from submucosal gastric tumors, including the use of jumbo biopsy forceps, the "biopsy-onbiopsy" technique, and the combination of strip biopsy and bite biopsy [1]. The use of endoscopic ultrasound-guided fine-needle aspiration is a less accepted method for the diagnosis of gastric submucosal lesions because its sensitivity for cytopathological diagnosis is only $60 \%[2,3]$. Although the needle-knife was originally described for facilitating biliary endoscopy, several reports have documented its usefulness in the management of intestinal luminal conditions $[4,5]$. This case demonstrates a further endoscopic application of the needleknife for such conditions.

\section{K. Mönkemüller, L. Fry, K. Drüding}

Department of Endoscopy, Desert Samaritan Medical Center, Mesa, Arizona, USA.

\section{References}

${ }^{1}$ Karita M, Tada M. Endoscopic and histologic diagnosis of submucosal tumors of the gastrointestinal tract using combined strip biopsy and bite biopsy. Gastrointest Endosc 1994; 40: 749-753

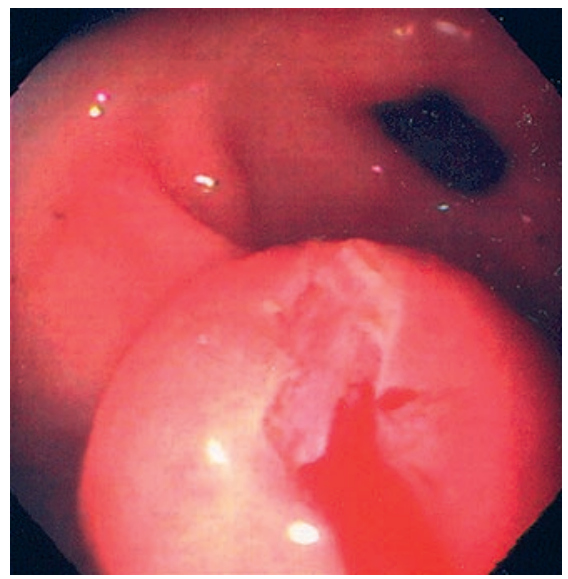

Figure 3 An incision, $1.5 \mathrm{~cm}$ in length, was made on the center of the mass, involving the mucosa and part of the submucosa.

${ }^{2}$ Rösch T. Endoscopic ultrasonography in upper gastrointestinal submucosal tumors: a literature review. Gastrointest Endosc Clin N Am 1995; 5: 609-615

${ }^{3}$ Sangha S, Gergeos F, Freter R et al. Diagnosis of ovarian cancer metastatic to the stomach by EUS-guided FNA. Gastrointest Endosc 2003; 58: 933 - 935

${ }^{4}$ Fry LC, Loudon R, Linder JD, Mönkemüller KE. Endoscopic removal of an entrapped snare around a polyp using a dual endoscope technique and needle knife. Gastrointest Endosc 2003; 57: $126-128$

${ }^{5}$ Ramirez FC, Zierer ST, Mills MR, Sanowski RA. Endoscopic removal of an entrapped foreign body from the sigmoid colon using a needle knife. Gastrointest Endosc 1996; 44: 84-85

Corresponding Author

\section{K. E. Mönkemüiller, M.D.}

East Valley Gastroenterology and Hepatology

9065 E. Wood Dr.

Scottsdale, AZ 85260

USA

Fax: $\quad+1-480-786-6996$

E-mail: monkemuller@aol.com 